\title{
Consent in radiology
}

\section{G R Howarth}

MB ChB, MMed (O + G), MPhil (Bioethics)

Department of Obstetrics and Gynaecology, and Department of Bioethics

Kalafong Hospital and University of Pretoria

Medicine has undergone a revolution, from the paternalistic approach where the doctor was considered to know best and expected to make decisions on behalf of the patient to the contemporary approach where the patient's autonomy is respected. ${ }^{1}$ It is now realised that under normal circumstances patients are best equipped to make decisions on their own behalf, based on their own values and beliefs. ${ }^{1}$ Philosophically the paradigmatic example of respecting an individual's autonomy is taking informed consent from them prior to an examination or procedure. ${ }^{1}$ The concept of informed consent before intervention is now not only a moral obligation, but has become a professional necessity and legal imperative. ${ }^{1-13}$

Once one has accepted that informed consent is mandatory, the basic structure of the consent process should be understood and followed (Table I). ${ }^{1}$ Under normal conditions where the threshold elements (voluntariness and decision-making capacity) are not in dispute, the major issues surround disclosure of information (Table II). "Taking informed consent in radiology represents a challenge due to the large array of imaging modalities (transmission, reflection and emission) and techniques. Risks may be inherent in the imaging modality (i.e. of radiation), in the technique (i.e. myelography) or in contrast agents utilised.

Radiologists also have to contend with the nuances of both screening and diagnostic tests. Radiologists perform screening tests (e.g. mammogra- phy), diagnostic tests (e.g. diagnosing fractures) and tests such as early obstetric ultrasound which is both a screening (nuchal translucency for chromosomal abnormalities, identification of structural abnormalities) and diagnostic (for viability of pregnancy, placental localisation, evaluating chorionicity and the number of fetuses in the case of multiple pregnancies and fetal measurements to confirm or establish gestational age) procedure. ${ }^{14}$ Among other things Table II shows the General Medical
Table I. The basic structure of the informed consent process (From Beauchamp and Childress ${ }^{1}$ )

Informed consent is not only a moral but also a legal obligation. Common law has established the general principle of informed consent. Touching a patient without valid consent could constitute assault. ${ }^{6}$ Further, if a health professional fails to obtain adequate consent and the patient subsequently suffers harm as a result of the treatment, albeit it as a result of adequate treatment and inherent risk, this may be a factor in a claim of negligence against the health professional involved. ${ }^{6}$

1. Threshold elements

1.1 Voluntariness: Any decisions made should be free of undue pressure.

1.2 Decision-making capacity: The patient should have the mental capacity to understand and make a decision about the procedure for which consent is being taken, as well as the ability to communicate that decision. In adults, in the absence of compelling evidence to the contrary decision-making capacity should be assumed to be intact.

2. Informational elements

2.1 Disclosure of information: Legally the doctor has to exercise due care by giving the necessary information. Morally the doctor has to give the necessary information for the patient to make an autonomous decision. The patient should also be informed that the purpose of the consent process is to facilitate autonomous choice. 2.2 Recommendations: The doctor may give his/her recommendations, based on what the doctor perceives to be in the patient's best interests.

2.3 Understanding: Prior to accepting a patient's authorisation the doctor should ascertain whether the patient has a substantial understanding of the salient facts.

3. Consent elements

3.1 Decision: The patient makes a decision based on the information disclosed. The decision is made according on the patient's own value system. The patient may decide to consent or decline the procedure.

3.2 Authorisation: If the patient decides to consent to the intervention, authorisation is given. There is no obligation for written authorisation; however, the greater the risk the more prudent it is to have signed authorisation.

It should be emphasised that the individual responsible for performing the investigation (in this case the radiologist) is morally and legally responsible for ensuring that the patient has given valid consent before treatment begins. ${ }^{6}$ 


\section{Table II. Disclosure of information}

When a doctor's diagnostic or therapeutic skills are evaluated in court, should they comply with what a body of reasonable medical practice considers good practice, then they must be accepted. This is not the case as regards the disclosure of information for informed consent. "Although the evidence of expert medical practitioners as to the completeness of disclosure may be persuasive, it will not be conclusive if the court finds that the standard of disclosure does not comply with the doctor's legal duty.

What the law is saying is that the level of disclosure is not dependent on the professional practice standard of disclosure as determined by the profession, but what the court considers a reasonable person would want to know prior to intervention. The standards of disclosure expected by health professionals' regulatory bodies might be higher than the minimum required by law. ${ }^{6}$ The General Medical Council in the United Kingdom advises that the doctor should try to ascertain the patient's individual needs and priorities when providing information on management options. For them the standard of disclosure is dependent on the subjective standard of the individual on whom the procedure is to be performed. ${ }^{5,6}$

Legal disclosure should include: ${ }^{11}$

- Advantages and disadvantages of the intervention, including 'material' and 'significant' risks of the intervention.

- Alternatives to the intervention.

- Risks incurred by declining the intervention.

- The option of a second opinion.

The term informed consent was initially legal in origin. From a moral viewpoint, taking informed consent has less to do with legal liability of disclosure and more to do with respecting the autonomous choice of the patient. 'Ethically the doctor should also try to ascertain the patient's individual needs and priorities when providing information on management options. Disclosure should include informing the patient that the reason for taking informed consent is to facilitate the patient's autonomy. Also explain that consent has limitations and that the patient may change his or her mind. The quality of informed consent as a process is more important than the quantity of information disclosed. ${ }^{\prime}$

The General Medical Council in the United Kingdom has given guidelines with regard to obtaining informed consent from patients undergoing medical procedures, including screening or diagnostic tests. ${ }^{5}$ The guidelines are specific and state that the following should be explained.

- The purpose of the test and whether it is a screening or diagnostic test and the distinction between the two.

- The likelihood of a positive and negative test.

- The concepts of sensitivity, specificity, false-negative and false-positive findings.

- The uncertainties and risks of the screening.

- The significant medical, social or financial consequences of screening.

- Follow-up plans, including counselling and support services.

Council's guidelines for information to be disclosed pertaining to screening and diagnostic tests.

Taking informed consent in radiology is further complicated by the need to discuss alternative options. Usually more than one imaging modality can be used to image for a particular condition and the different modalities and techniques each have their own unique risks and different sensitivities and specificities.

When performing these examinations we often forget the detrimental side-effects of screening, the anxieties, false alarms, unnecessary interventions and over-management, and from a potential medico-legal point of view, false reassurances. ${ }^{15-17}$

\section{Understanding screening and diagnostic tests}

Not detecting an abnormality is often equated with negligence as most patients have unrealistic expectations of screening and diagnostic tests. ${ }^{18-20}$ Doctors must try to establish a reasonable level of understanding and expectation in their patients. ${ }^{21,22}$

Patients need to acquire a basic conceptual understanding of the concepts of prevalence, sensitivity, specificity, and positive and negative predictive values. Prevalence of a condition is probably the easiest to understand and may be presented as either percentages or ratios. Sensitivity, specificity, positive and negative predictive values are more difficult concepts to comprehend. Patients may grasp them more intuitively if one utilises the concepts of true-positives, false-positives, true-negatives and false-negatives. A patient should understand that a test may be positive; if positive it may be a true-positive or a false-positive. False-positives are a reality of any screening programme; they are alarming and anxiety-provoking and usually lead to further testing, which if invasive constitutes a potential risk to the normal fetus. If the test is negative it may be a truenegative or a false-negative. Like falsepositives, false-negatives are a reality of any screening programme; they are falsely reassuring and if not explained and understood may lead to subsequent litigation. The patient should 
also understand that where the prevalence of a condition is low, the majority of positive screening results will be falsely positive, while fortunately the overwhelming majority of negative screening results are true-negatives.

As in other areas of medicine one has the problem of extrapolating population-based risks to an individual patient. As an example, should nuchal translucency screening indicate a high risk of trisomy 21 , the populationbased risk of losing a pregnancy due to an amniocentesis is between $0.5 \%$ $(1: 200)$ and $1 \%(1: 100)$, but in reality the risk for the individual patient is all or nothing. ${ }^{23,24}$ The woman either retains or loses the baby. Ironically due to the low prevalence of the condition, most of the babies lost during amniocentesis will be chromosomally normal.

\section{Conclusion}

It would appear that unhappiness with mammography is a common cause for litigation. ${ }^{25}$ Practitioners who would possibly like to take refuge behind the fact that many of their colleagues do not take informed consent prior to radiological investigation should beware. ${ }^{2-6}$ A patient is entitled to informed consent and failure to take adequate consent may result in admonishment. The courts are under no obligation to compare the practitioner's practice with contemporary practice or the opinion of experts. ${ }^{.1}$ The precedent has been set in South African law and the standard of disclosure is dependent on the information that a reasonable patient would require prior to intervention. ${ }^{13}$ The standards of disclosure expected by the health professionals' regulatory bodies might be higher than the minimum required by law. The General Medical Council in the United Kingdom advises that the doctor should try to ascertain the patient's individual needs and priorities when providing information on management options. ${ }^{5.6}$ For them the standard of disclosure is dependent on the subjective standard of the individual on whom the procedure is to be performed.

Surely any true moral agent would also feel obliged to inform a patient fully before any intervention? Obtaining informed consent also serves the interests of the radiologist by reducing the risk that subjects will pursue legal action when their expectations about the intervention are not met. The possibility of later unhappiness and even litigation may be greatly reduced by early disclosure, discussion, and the opportunity to decline intervention. The importance of informed consent in radiology cannot be over-emphasised. Informed consent should be seen as a friend not a fiend, a help not a hindrance.

\section{References}

1. Beauchamp TL, Childress JF. Principles of Biomedical Ethics. 5th ed. Oxford: Oxford University Press, 2001: 77-104.

2. South African Medical Association. Doctors' Code of Conduct. Cape Town: SAMA, 1998. http://www.samedical.org/

3. South African Medical Association. Patients' Rights, 1998, http://www.samedical.org/

4. Department of Health (South Africa). National Patients' Rights Charter. Pretoria: DOH, 1999. http://www.samedical.org/

5. General Medical Council (UK). Seeking Patients' Consent: The Ethical Considerations. London: General Medical Council, 1999.

6. Department of Health (UK). Reference Guide to Consent for Examination or Treatment. London: DOH, 2001. http://www.doh.gov.uk/ consent.htm
7. The Royal College of Radiologists. Consent By Patients to Examination or Treatment. London: RCR, 1991. http://www.rcr.ac.uk/pubtop.asp? Publication $I D=121$

8. The Royal College of Radiologists. Guidance on Consent by Patients to Examination or Treatment in Departments of Clinical Radiology. London: RCR, 1999. http://www.rcr.ac.uk/pubtop.asp?Publication $\mathrm{ID}=62$

9. The Royal College of Radiologists. Good Practice for Clinical Radiologists. London: RCR, 1999. http://www.rcr.ac.uk/pubtop.asp? PublicationID $=59$

10. The Royal College of Radiologists. Making Your Radiology Services More Patient Friendly. London: RCR, 2000. http://www.rcr.ac.uk/ pubtop.asp?PublicationID $=147$

11. Brahams L. Doctor's duty to inform patient of substantial or special risks when offering treatment. Lancet 1985; I: 528-530.

12. Constitution of the Republic of South Africa (Act 108, 1996), Chapter 2, The Bill of Rights. http://www.polity.org.za/govdocs/constitution/saconst.html

13. Castell v. De Greef 1994 (4) SA 408 (C).

14. Seed JW. The routine or screening obstetrical ultrasound examination. Clin Obstet Gynecol 1996; 39: 814-830.

15. Hall S, Bobrow M, Marteau T. Psychological consequences for parents of false-negative results on prenatal screening for Down's syndrome: retrospective interview study. BMJ 2000; 320: 407-412.

16. Stewart-Brown S, Farmer A. Screening could seriously damage your health (editorial). BM] 1997; 314: 533.

17. McFayden A, Gledhill J, Whitloa B, Economides D. First trimester ultrasound screening; carries ethical and psychological implications (editorial). BMJ 1998; 317: 694-695.

18. Cockburn J, Redman S, Hill D, Henry E. Public understanding of medical screening. J Med Screen 1995; 2: 224-227.

19. Anonymous. The gap between expectations and reality. BMJ 2000; 320: 1348. http://bmj.com/cgi/content/full/320/7246/0

20. The right to a perfect baby. Independent, 22 August 1992: 3.

21. McCall Smith A. Obtaining consent for examination and treatment (editorial). BMJ 2001; 322: 810-811.

22. Austoker J. Gaining informed consent for screening. BMJ 1999; 319: 722-723.

23. Royal College of Obstetricians and Gynaecologists. Report of the working party on ultrasound screening for fetal abnormalities. London: RCOG Press, 1997.

24. Tabor A, Philip J, Madsen M, Bang J, Obel EB, Norgaard-Pedersen B. Randomised controlled trial of genetic amniocentesis in 4606 low-risk women. Lancet 1986; I:1287-1293.

25. Wilson RM. Screening for breast and cervical cancer as a common cause for litigation. BM] 2000; 320: 1352-1353. 